\title{
An investigation of thermo-hydro- geochemical processes in a standing column well intersected by a fracture
}

\section{F. Eppner}

\section{ABSTRACT}

Local thermal and chemical conditions may favor minerals' scaling which can cause undesirable operational problems to standing column well systems. Precipitation may reduce heat exchange in the well and the heat exchanger and increase pressure drops in the systems components, as well as the drawdown in the well. In this paper, a coupled thermo-bydro-geochemical model simulating the operation of a standing column well is used to illustrate the link between the temperature and the reaction rate of calcite. The results demonstrate that bleeding only 10\% of the pumped water allows to get rid of calcium ions in solution in the well and reduces substantially the precipitated calcite mass. Our simulations clearly indicate that groundwater flow induced by the bleed mainly occurs in the fracture since significant chemical variations are observed downstream of the fracture. We expect that the findings presented in the paper will help demystify the complex thermo-hydro-geochemical behaviour of standing column wells installed in sedimentary rocks.

\section{INTRODUCTION}

Standing column wells (SCWs) present an important energy savings potential in dense urban centers. Although most applications of SCWs in Northeastern United States did not report mineral scaling problems, it is known from past experiences with open-loop systems (Stanasel et al., 2006; Gunnlaugsson 2012; Ma et al., 2012) that mineral precipitation can impede the operation of the heat exchangers and possibly clog the fractures surrounding a SCW. It is likely that these issues will become more common as more SCWs will be installed in sedimentary environments. Understanding the chemical mechanisms induced by the operation of a SCW in sedimentary rocks is then of primary importance.

Indeed, the chemical composition of groundwater in a SCW undergoes important variations throughout the year. These variations are mainly due to fluctuations of groundwater temperature induced by heat pumps' operation, $\mathrm{CO}_{2}$ degassing caused by pumping and reinjection of groundwater and/or groundwater supply from a fracture having a different chemical signature or temperature. Operational problems arise in response to the increase in roughness of pipes' surface, to pressure drops and to the drawdown in the SCW, as well as to the decrease in heat transfer with the geological formation and the coolant in the heat exchanger.

A thermo-hydro-geochemical (THG) model coupling groundwater flow, heat transfer and reactive transport of dissolved species has been developed recently (Eppner et al., 2015, 2016; Pasquier et al.; 2016) to investigate the risks of calcite dissolution and precipitation in the vicinity of a SCW. In this article, this THG model is used to explain

Fanny Eppner (fanny.eppner@polymtl.ca) is a PhD student, Philippe Pasquier is a professor of hydrogeology and geothermal energy and Paul Baudron is a professor of hydrogeology at École Polytechnique of Montréal. 
complex interactions between thermal, hydraulic and geochemical processes which may cause precipitation and dissolution of calcite. The beneficial impact of the bleed on the calcite precipitation rate in a presence of a fracture is also presented and discussed. In addition, the modification of chemical groundwater composition in the well caused by supply of water from a fracture is illustrated.

\section{GEOCHEMICAL REACTIONS INVOLVING CALCITE}

Precipitation and dissolution of calcite $\left(\mathrm{CaCO}_{3(\mathrm{~s})}\right)$ in carbonate rocks is quite common. Indeed, this widespread mineral may chemically react with groundwater and release some mobile ions in solution, thus promoting local dissolution of the carbonate rock. Alternatively, if the local conditions in the aquifer promote precipitation, some ions may combine together and create solid calcite precipitates (Brantley et al., 2008). The calcite crystals will grow from a solid nucleus (usually a mineral surface or a solid particle in suspension in water) and reduce the fracture' aperture or accumulate in areas of low velocity such as horizontal pipes (see Figure 1).

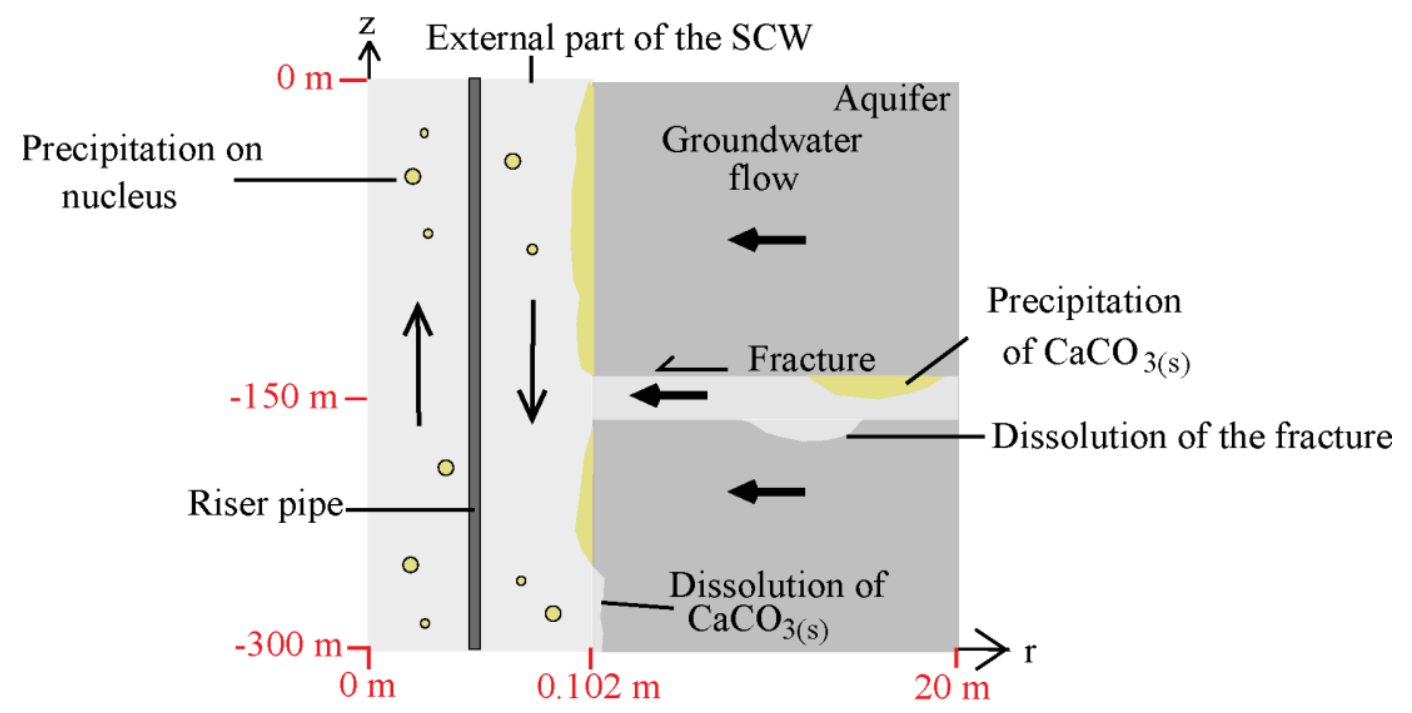

Figure 1 Geometry of the SCW model and illustration of precipitation and dissolution of calcite on particles in suspension and mineral surface in groundwater circulating in the well and on the borehole walls.

Two types of chemical reactions control the precipitation or dissolution rate of calcite. The first type involves six fast equilibrium reactions describing the reactions taking place in the aqueous phase, while the second type involves three slow reversible kinetic reactions occuring at the surface of solid particles in suspension or minerals. These nine chemical reactions are:

Equilibrium reactions - Fast

$$
\begin{aligned}
& \mathrm{H}^{+}+\mathrm{OH}^{-} \longleftrightarrow \mathrm{H}_{2} \mathrm{O} \\
& \mathrm{H}^{+}+\mathrm{CO}_{3}^{2-} \longleftrightarrow \mathrm{HCO}_{3}^{-} \\
& \mathrm{Ca}^{2+}+\mathrm{HCO}_{3}^{-} \longleftrightarrow \mathrm{CaHCO}_{3}^{+} \\
& \mathrm{H}^{+}+\mathrm{HCO}_{3}^{-} \longleftrightarrow \mathrm{H}_{2} \mathrm{CO}_{3} \\
& \mathrm{Ca}^{2+}+\mathrm{CO}_{3}^{2-} \longleftrightarrow \mathrm{CaCO}_{3(a q)} \\
& \mathrm{H}^{+}+\mathrm{CaOH}^{+} \longleftrightarrow \mathrm{Ca}^{2+}+\mathrm{H}_{2} \mathrm{O}
\end{aligned}
$$

Kinetic reactions - Slow

$$
\begin{aligned}
& \mathrm{CaCO}_{3(s)}+\mathrm{H}^{+} \underset{k_{-1}}{\stackrel{k_{1}}{\longrightarrow}} \mathrm{Ca}^{2+}+\mathrm{HCO}_{3}^{-} \\
& \mathrm{CaCO}_{3(s)}+\mathrm{H}_{2} \mathrm{CO}_{3}^{o} \underset{k_{-2}}{\stackrel{k_{2}}{\longrightarrow}} \mathrm{Ca}^{2+}+2 \mathrm{HCO}_{3}^{-} \\
& \mathrm{CaCO}_{3(s)}+\mathrm{H}_{2} \mathrm{O} \underset{k_{-3}}{\stackrel{k_{3}}{\longrightarrow}} \mathrm{Ca}^{2+}+\mathrm{HCO}_{3}^{-}+\mathrm{OH}^{-}
\end{aligned}
$$


All these reactions are temperature dependent (see Appelo and Postma 1993; Plummer et al., 1978), which has some practical consequences. For instance, an increase of water temperature reduces calcite solubility and promotes its precipitation, which explains why calcite crusts are often found in domestic hot water tanks. Similarly, elevating water temperature decreases $\mathrm{CO}_{2}$ solubility and promotes its degassing from the water free surface to the atmosphere, which again promotes calcite precipitation. Since the chemical species involved in dissolution/precipitation reactions are relatively mobile in the aqueous phase, the ions can be transported by advection, diffusion and dispersion mechanisms and precipitate anywhere else in the system where the local conditions are favorable to precipitation.

\section{THERMO-HYDRO-GEOCHEMICAL MODEL}

This section describes briefly the SCW model used in this study to allow the reader appreciate the results presented hereinafter. More details on the simulation framework, boundary conditions, relation between reaction constants $\left(k_{\mathrm{i}}, k_{-\mathrm{i}}\right)$ and temperature, or connection between fracture' aperture and calcite precipitation can be found in Eppner et al., (2015), Nguyen et al., (2015) and Pasquier et al., (2016).

\section{Governing equations}

The SCW model couples three models, namely a groundwater flow model (Eq. 2), a heat transfer model (Eq. 3) and a geochemical model (Eq. 4) supplying the species concentrations (c) over the simulation domain. The temperature is obtained by considering heat transfer by advection and conduction mechanisms, while the species concentrations are obtained by considering that advection, diffusion and dispersion mechanisms drive species transport. Recall that all chemical reactions are temperature dependent. The groundwater flow is simulated by solving the conservation equation and Darcy's law, as expressed by the following equations:

$$
\rho S_{s} \frac{\partial p}{\partial t}+\nabla \cdot(\rho v)=0 \text { with } v=-\frac{K}{\rho g}\left(\nabla p+\rho g \nabla D_{v}\right)
$$

where $\rho$ is the fluid density, $S_{s}$ is the storage coefficient, $p$ is the pressure, $t$ is the time, $v$ is Darcy's velocity, $K$ is the hydraulic conductivity, $g$ is the gravitational acceleration and $D_{v}$ is the vertical coordinate. Darcy's velocity is integrated in the heat transfer equation with the aim to define the temperature $(T)$ over the entire domain through:

$$
\rho C_{p} \frac{\partial T}{\partial t}+\rho C_{p} v \cdot \nabla T=\nabla \cdot(\lambda \nabla T)
$$

with $\lambda$ and $\rho C_{p}$ which are the equivalent thermal conductivity and volumetric heat capacity respectively. Finally, $v$ and $T$ are integrated in the reactive transport equation to define the activity of the species at each node of the model by:

$$
\varphi \frac{\partial}{\partial t} \boldsymbol{\Gamma}=\nabla \cdot(D \nabla \boldsymbol{\Gamma})-\nabla \cdot(v \boldsymbol{\Gamma})+\boldsymbol{U} \boldsymbol{S}_{k}^{\prime} \boldsymbol{r}_{k}
$$

where $\varphi$ is the ground porosity, $\Gamma$ is the vector of species' total concentration, $D$ is the diffusion coefficient of the total concentration which includes the molecular diffusion and dispersivity, $\boldsymbol{U}$ is a transformation matrix, $\boldsymbol{S}_{\boldsymbol{k}}$ is the stoichiometric matrix for the kinetic reactions, $\boldsymbol{r}_{\boldsymbol{k}}$ is a vector of the reaction rates of the kinetic reactions and ' is the transpose operator. The matrix and the vectors are described in details in Eppner et al., (2015).

The species involved in the model (see Eq. 1) are grouped in three total concentrations $\left(\Gamma_{i}\right)$, allowing to solve only three transport equations (Eq. 4) instead of nine according to the Tableaux method (Morel and Hering 1993; Eppner et al., 2015). This operation greatly simplifies the simulation burden and reduces calculation time. To simulate 
the geochemical reactions and to couple them with transport processes, a system of nine equations and nine unknowns (one for each concentration) has also to be built and solved over the simulation domain. For the first six equations, the following formulation is used (Saaltink et al., 1998; Holzbecher 2012):

$$
S_{e} \cdot \log \alpha-\log K_{e q}=0
$$

where $\boldsymbol{S}_{\boldsymbol{e}}$ is the stoichiometric matrix for the equilibrium reactions, $\alpha$ is the vector of the activity of the species and $\boldsymbol{K}_{e q}$ is the vector of the equilibrium constants of the equilibrium reactions. To complete the system of nine equations, three additional equations are added for each node of the simulation domain:

$$
\boldsymbol{U} \cdot \mathbf{c}-\boldsymbol{\Gamma}=0
$$

The kinetic reactions described by the term $\boldsymbol{U} \boldsymbol{S}_{\boldsymbol{k}}^{\prime} \boldsymbol{r}_{k}$ in Eq. 4 are simulated by the following source term:

$$
\boldsymbol{U} \boldsymbol{S}_{k}^{\prime} \boldsymbol{r}_{k}=\left(\begin{array}{c}
\hat{R}_{1}+\hat{R}_{2}+\hat{R}_{3} \\
-\hat{R}_{1}-\hat{R}_{2}-\hat{R}_{3} \\
-\hat{R}_{1}-\hat{R}_{2}-\hat{R}_{3}
\end{array}\right)
$$

where $\hat{R}_{i}$ is the reaction rate of the kinetic reactions (Eppner et al., 2015 and Plummer et al., 1978). The matrix $\boldsymbol{U}$, used in Eq. 6 for equilibrium reactions and in Eq. 7 for kinetic reactions, allows to link both reaction types.

\section{Boundary conditions and input parameters}

Geometry, boundary conditions and input parameters used to solve Eq. 2 to 7 reflect the materials, geometry (water-filled borehole, raiser pipe, aquifer, fracture) and operation of a typical SCW. Indeed, the model integrates especially the pumping and reinjection operations, the drawdown caused by the bleed (if activated) and the temperature variation induced by the heat pump at the $\mathrm{SCW}$ ' inlet defined by $\mathrm{Q}_{\mathrm{g}} /\left(\vec{V} \cdot \rho \mathrm{C}_{\mathrm{p}}\right)$, where $\mathrm{Q}_{\mathrm{g}}$ is the heating or cooling load presented in Figure 2 and $\dot{V}$ is the pumping rate. It is worth nothing that water in the aquifer (beyond the model radius) has a constant temperature throughout the year of about $10{ }^{\circ} \mathrm{C}$. The initial species concentration and the concentrations prescribed along the lateral boundary are at chemical equilibrium and varie with depth and temperature (a $p H$ of 7 and a $P C O_{2}$ of $10^{-1.39}$ atm have been used to define the initial groundwater composition). Finally, the main thermal and hydraulic parameters integrated in the model are presented in Table 1 below.

Table 1. Parameters used in the simulations.

\begin{tabular}{ccccccc}
\hline Parameter & Unit & Symbol & Fluid (f) & Soil (a) & Pipe (p) & Fracture (fr) \\
\hline \hline Hydraulic conductivity & $(\mathrm{m} / \mathrm{s})$ & $K$ & 1000 & $1.0 \mathrm{e}-6$ & $1.0 \mathrm{e}-9$ & $5.26($ initial) \\
Pumping rate & $1 / \mathrm{min}$ & $\dot{V}$ & 189 & - & - & - \\
Specific storage & $1 / \mathrm{m}$ & $S s$ & $4.0 \mathrm{e}-6$ & $5.0 \mathrm{e}-5$ & $1.3 \mathrm{e}-7$ & $5.0 \mathrm{e}-5$ \\
Porosity & - & $\varphi$ & 1 & 0.1 & $1.0 \mathrm{e}-5$ & 1 \\
Thermal conductivity & $\mathrm{W} /(\mathrm{m} \cdot \mathrm{K})$ & $k$ & 0.6 & 2.5 & 0.1 & $0.6-2.5^{*}$ \\
Volumetric heat capacity & $\mathrm{kJ} /\left(\mathrm{m}^{3} \cdot \mathrm{K}\right)$ & $C v$ & 4200 & 2160 & 1560 & $2160-4200^{*}$ \\
Molecular diffusion & $\mathrm{m}^{2} / \mathrm{s}$ & $D_{f}$ & $1.0 \mathrm{e}-2$ & $1.0 \mathrm{e}-9$ & - & $1.0 \mathrm{e}-5$ \\
Dispersivity & $\mathrm{m}$ & $D_{l} / D_{t}$ & $0 / 0$ & $6.7 / 0.67$ & - & $0.1 / 0$ \\
(longitudinal/transversal) & & & & & \\
\hline
\end{tabular}

* The fracture is consisting of soil and water, meaning that this parameter varies between the values applied for the soil and water. 
To illustrate the THG behavior of a SCW intersected by a fracture, the equations and parameters presented previously were integrated in a SCW model of $300 \mathrm{~m}$ containing a fracture of $3 \mathrm{~mm}$ thick at a depth of $150 \mathrm{~m}$. Two one-year simulations (from January 1 to December 31) were achieved (with a constant bleed of $10 \%$ and without bleed) using the heating and cooling loads illustrated in Figure 2 (a). Notice that negative and positive loads are respectively used for heating and cooling.

\section{ILLUSTRATION OF THG PROCESSES}

To illustrate a first THG process, one can see on Figure 2 (b) and (c) the evolution of the SCW inlet and outlet fluid temperature along with the evolution of $\mathrm{Ca}^{2+}$. This figure exemplifies the strong influence of temperature on calcite reaction rate and therefore on $\mathrm{Ca}^{2+}$ concentrations (as well as on the other species involved in Eq. 1). The correlation observed between $T$ and $\mathrm{Ca}^{2+}$ is easily explained by the fact that as the fluid temperature rises, calcite precipitation is promoted at the well' entrance, which consumes ions of $\mathrm{Ca}^{2+}$ and $\mathrm{CO}_{3}{ }^{2-}$ to form $\mathrm{CaCO}_{3(\mathrm{~s}) \text {. }}$.

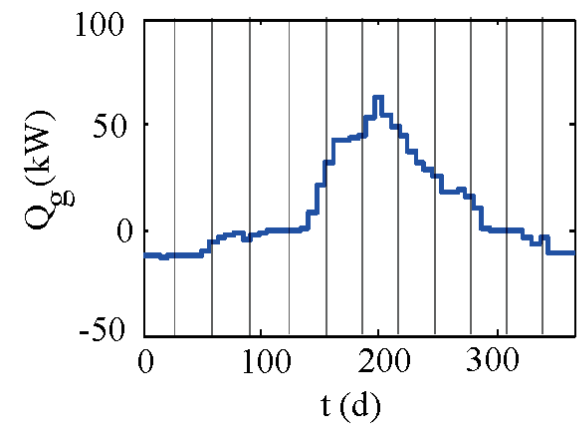

(a)

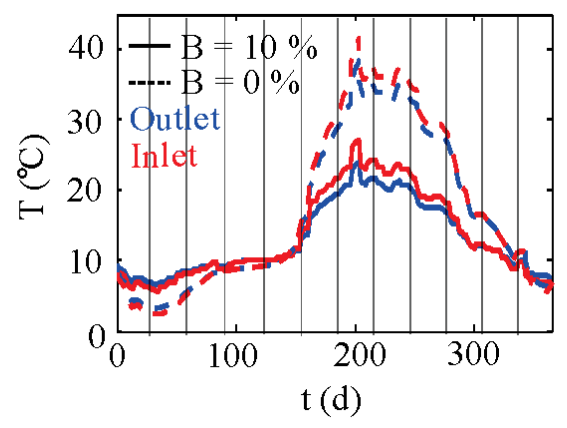

(b)

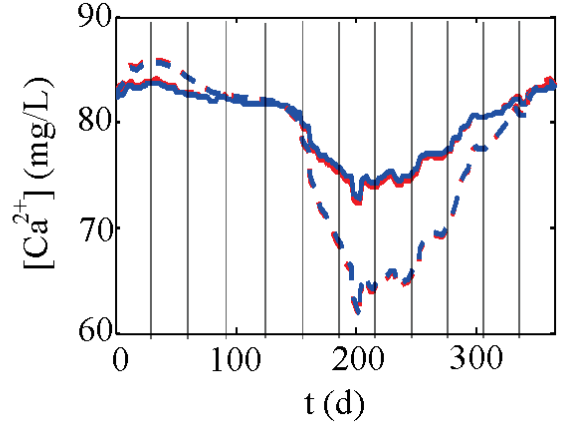

(c)

Figure 2 Temporal evolution of (a) heating and cooling loads, (b) temperature and (c) $\mathrm{Ca}^{2+}$ concentration at the inlet and outlet of the well, with and without a $10 \%$ bleed (B).

The THG solutions over the simulation domain is also instructive. For instance, Figure 3 compares Darcy velocities, streamlines, temperatures and $\mathrm{Ca}^{2+}$ concentration for a simulation time step corresponding to 12 months of operation (December 31 th). In winter, heat extraction in the well cools the surrounding geological formation, whereas a warm zone is observed between 0.5 and $8 \mathrm{~m}$, corresponding to the effect of heat injection during the previous summer. Temperature oscillations greatly influences $\mathrm{Ca}^{2+}$ concentration. Indeed, the hottest areas have a lower $\mathrm{Ca}^{2+}$ concentration, while the coolest zones are calcium-enriched. This behavior is explained by the fact that an increase in temperature promotes the reactions in the direction allowing to decrease calcium concentration. Finally, the distribution of calcium shows that advective transport is not a dominant mecanism in most of the aquifer, but an important one around the fracture.

Figure 4 presents vertical profiles of the temperature, $\mathrm{Ca}^{2+}$ concentration and overall calcite reaction rate $\left(\tilde{R}=\hat{R}_{1}+\hat{R}_{2}+\hat{R}_{3}\right)$ in the ascending and descending fluids of the SCW in July and December. Note that a negative overall rate indicates that the rate of precipitation exceeds the rate of dissolution and inversely when the rate is positive. We can observe that without bleed, injection of warm water in the SCW during summer (Fig. 4 (a)) increases precipitation of calcite (see the negative rate on Fig. 4 (c) from $z=0$ to $100 \mathrm{~m}$ ) and decreases $\mathrm{Ca}^{2+}$ concentration (Fig. 4 (b)). Around a depth of $100 \mathrm{~m}$, the reaction rate reaches zero and becomes positive between a depth of 100 and $300 \mathrm{~m}$ due to the simultaneous drop of temperature and calcium concentration, leading to a state of undersaturation with respect to calcite. Dissolution of calcite is then favored at the base of the well and in the central pipe, increasing slightly calcium concentration. In winter, the opposite behavior is observed and the injection of cold water at the top of the SCW causes dissolution of calcite along the borehole wall until a depth of $150 \mathrm{~m}$ (Fig. 4 (d, e, f)), and precipitation along the remaining path. 


\section{CONTROLLING SPECIES CONCENTRATION BY BLEED}

Bleed activation is a key component of the operation of SCWs as it generates a beneficial groundwater flow toward the well (recall that the far field temperature is constant at about $10{ }^{\circ} \mathrm{C}$ ). Comparing Fig. 4 (a) and (d) clearly confirms the fact that bleed allows reducing the fluid temperature in cooling mode and to increase it in heating, thus leading to better heat pump performances. From a geochemical perspective, bleeding a fraction of the pumped water also allows to get rid of the ions in solution and attenuates the annual fluctuations of species concentration. This has a direct impact on the calcite reaction rate and on the chemical signature of the water circulating in the SCW. Indeed, the mean precipitation rate observed in July and Decembre (Fig. 4 (c and f)) are closer to zero when the bleed is activated, indicating an environment less reactive and therefore less prone to calcite dissolution and precipitation.

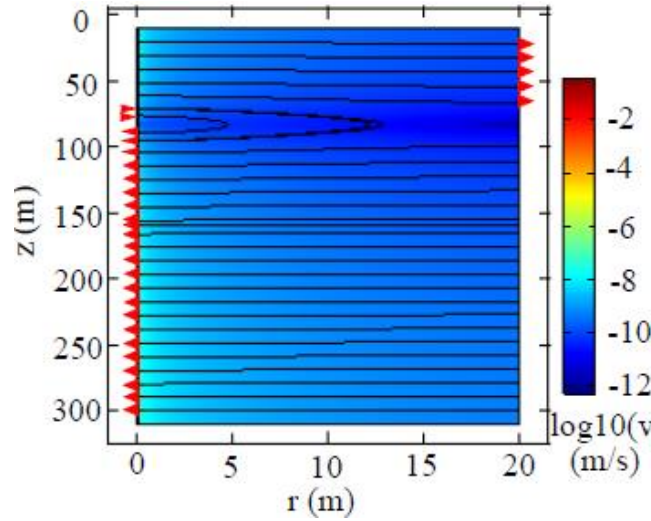

(a)

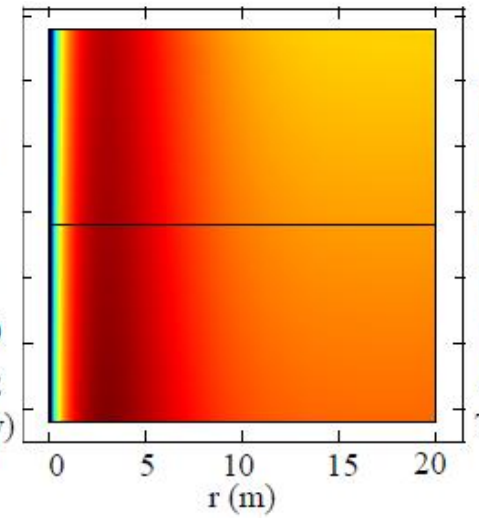

(b)

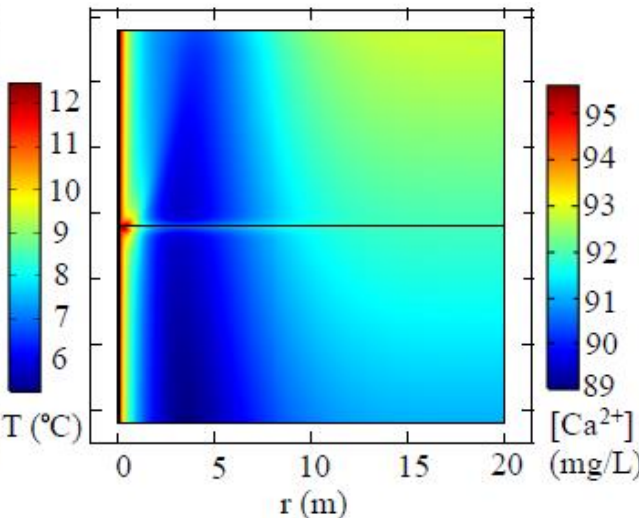

(c)

Figure 3 Solutions of (a) the hydraulic model (Darcy velocity and streamlines), (b) the heat transfer model (temperature) and (c) the geochemical model $\left(\mathrm{Ca}^{2+}\right.$ concentration) at the end of the year (December $\left.31^{\text {th }}\right)$. Notice that only calcium has been presented here but the concentration of the other species is also available.

\section{IMPACT OF THE FRACTURE}

It is clear from Figure 4 that groundwater flow induced by the bleed mainly occurs in the fracture since significant variations of the parameters presented are observed in the descending fluid at a depth of $150 \mathrm{~m}$. Indeed, in July the reaction rate of calcite varies abruptly due to the supply of calcium and the temperature decline caused by the groundwater inflow from the fracture (Fig. 4(a, b, c)). Similarly, at the fracture's depth in December the overall reaction rate varies locally owing to the calcium depleted groundwater inflow. Notice that in December, the $\mathrm{Ca}^{2+}$ concentration is relatively high in the descending fluid due to the important rate of dissolution, explaining why the water supplied by the fracture reduces the calcium concentration in the well. It is worth nothing that the water below the fracture is closer to chemical equilibrium ( $\tilde{R}$ tends to 0$)$ throughout the year due to the supply of water from the aquifer. In this study, a single fracture located at a depth of $150 \mathrm{~m}$ was considered but additional work should be done to confirm the generality of this result.

\section{LOCATION OF PRECIPITATION AND DISSOLUTION}

The overall reaction rate is useful for understanding the mechanisms leading to precipitation and dissolution of calcite. However, this variable does not easily represent the magnitude of the processes within the well. The cumulative mass of calcite is more meaningful for quantifying and localizing precipitation and dissolution processes. Figure 5 illustrates the cumulative calcite mass after one year between the riser pipe and the geological formation, with and without a continuous $10 \%$ bleed. Negative values indicate a dissolved mass, while positive values express a precipitated mass. At the top of the SCW, an accumulation of about $0.45 \mathrm{~kg}$ of calcite is observed without bleed, 
against $0.2 \mathrm{~kg}$ with bleed. In addition, when the bleed is not active, calcite is dissolved at the base of the SCW, which consequently releases $\mathrm{Ca}^{2+}$ ions in solution and increases the risk of precipitation elsewhere in the system. The precipitated calcite mass is however relatively small for the size of the well. Indeed, the mass balance after an operation of one year in the SCW annulus is $0.95 \mathrm{~kg}$ with bleed and $0.25 \mathrm{~kg}$ without bleed.

Notice that in some specific cases, the bleed may increase the rate of precipitation of calcite. For instance, assuming that $\mathrm{CaCO}_{3(\mathrm{~s})}$ precipitates on particles in suspension, which will accumulate at the base of well, an operation without bleed is expected to be more advantageous, since the base of the descending fluid is undersaturated with respect to calcite, preventing calcite scaling. Moreover, when $\mathrm{CO}_{2}$ degassing is observed at the top of the SCW, calcite scaling is more important when the bleed is active. Indeed, $\mathrm{CO}_{2}$ supply from the aquifer allows to maintain a high $\mathrm{CO}_{2}$ flux in direction to the atmosphere, significantly increasing the rate of precipitation. Contrariwise, without bleed, the reserve in $\mathrm{CO}_{2}$ decreases in function of time, therefore reducing the negative impact of this phenomenon.

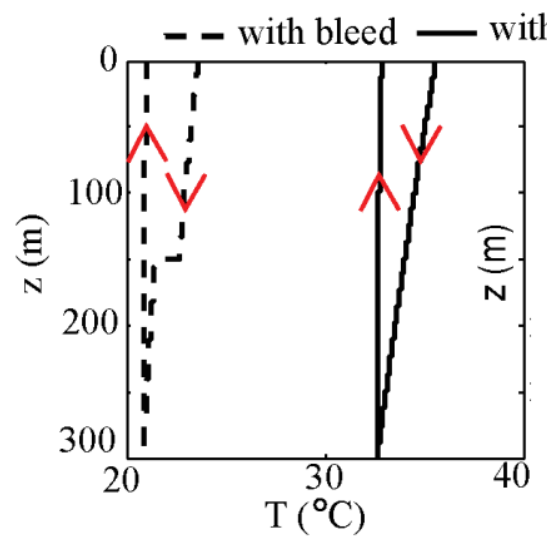

(a)

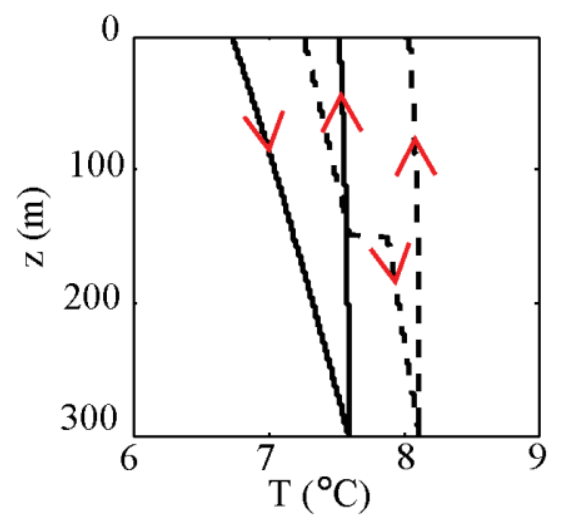

(d)

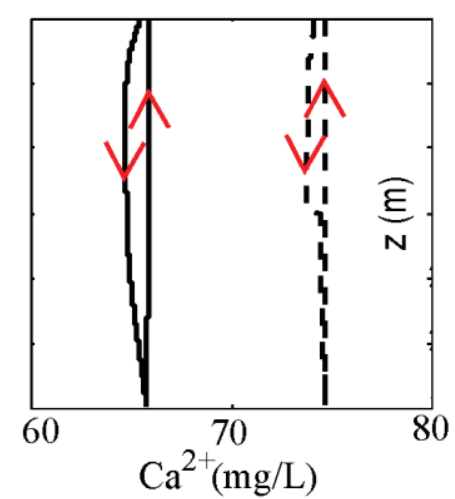

(b)

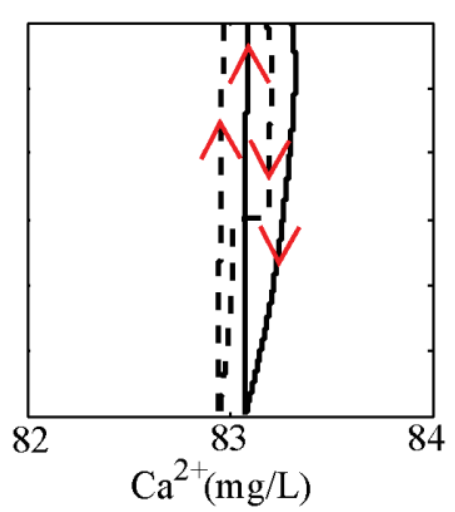

(e)

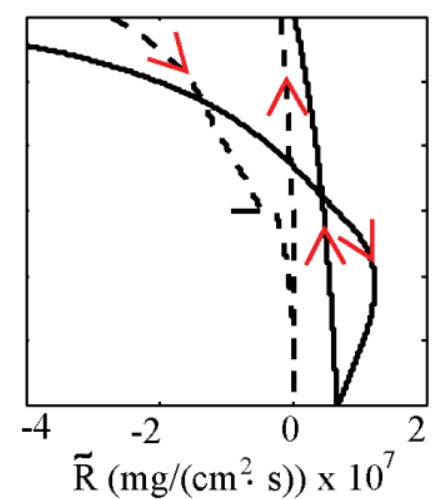

(c)

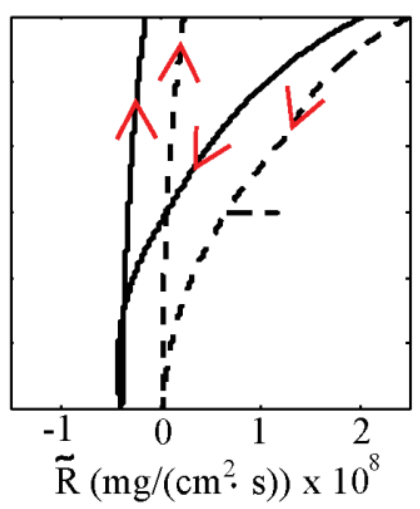

(f)

Figure 4 Profiles of the temperature, the concentration in $\mathrm{Ca}^{2+}$ and the overall rate of reaction of calcite as a function of depth in the ascending and descending fluids with a $10 \%$ bleed (in dashed line) and without bleed (in solid line) in July (a, b, c) and December (d, e, f).

\section{PReVenting geOChemicAl PROBlems}

The significative precipitation rate at the SCW inlet suggests that calcite precipitation may occur in the heat pump, heat exchanger, above ground pipes and upper portion of the SCW, which may consequently decrease the heat exchange between the groundwater and the refrigerant, increase pressure drops in the systems components, and possibly the drawdown in the SCW. Therefore, controlling mineral scaling in the mechanical equipments and SCW may prove important. Our observations indicate that a constant $10 \%$ bleed helps reducing calcite precipitation in the 
SCW and could therefore be used as a simple and effective mitigation measure for the SCW itself. However, if the groundwater bled from the SCW is reinjected in the original aquifer through an injection well (as required in some jurisdictions), it is likely that precipitation will occur in the injection well and surrounding fracture network. Additional works will be required to quantify the clogging risk of the injection well and identify effective mitigation measures such as, for example, use of water treatment system.

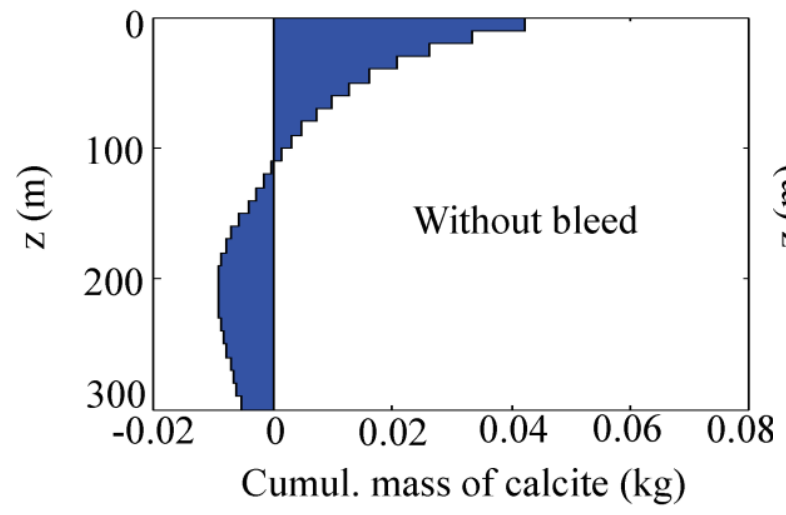

(a)

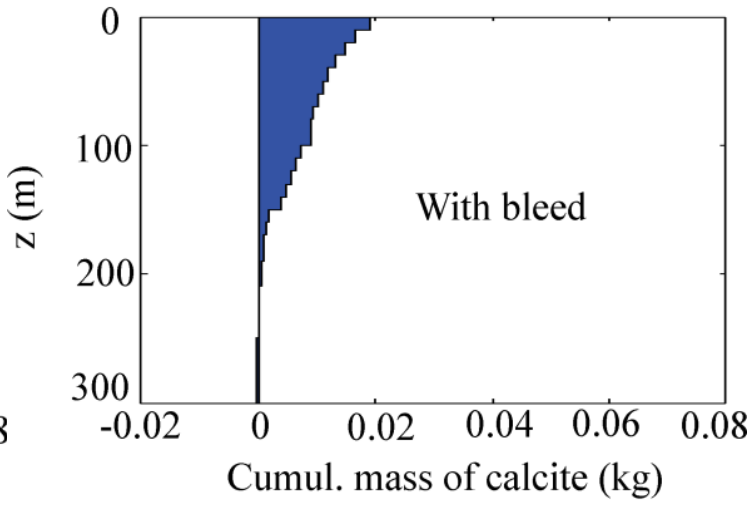

(b)

Figure 5 Cumulative mass of calcite in the external part of the well at the end of the year (a) without bleed and (b) with bleed. Negative values indicate a dissolved mass, while positive values express a precipitated mass.

\section{CONCLUSION}

With the aim to control minerals scaling in SCWs, identifying processes leading to fluid sursaturation with respect to a certain mineral is important. This study demonstrates that temperature controls the rate of reaction of calcite and therefore, the chemical signature of the water in the well. However, the bleed can be used to mitigate yearly temperature fluctuations in the well and consequently reduce the accumulation of calcite on borehole walls at the top of the SCW. Moreover, when a fracture is present in the aquifer, groundwater flow induced by the bleed mainly occur in this preferential flow path. Chemical signature of the descending fluid before and after the fracture are therefore significantly different. We hope that this new knowledge favors the installation of SCWs in carbonate rocks. Notice that the results presented in this paper are valid for the parameters fixed in the model. With another initial groundwater composition for instance, the results and conclusions could be somehow different

\section{NOMENCLATURE}

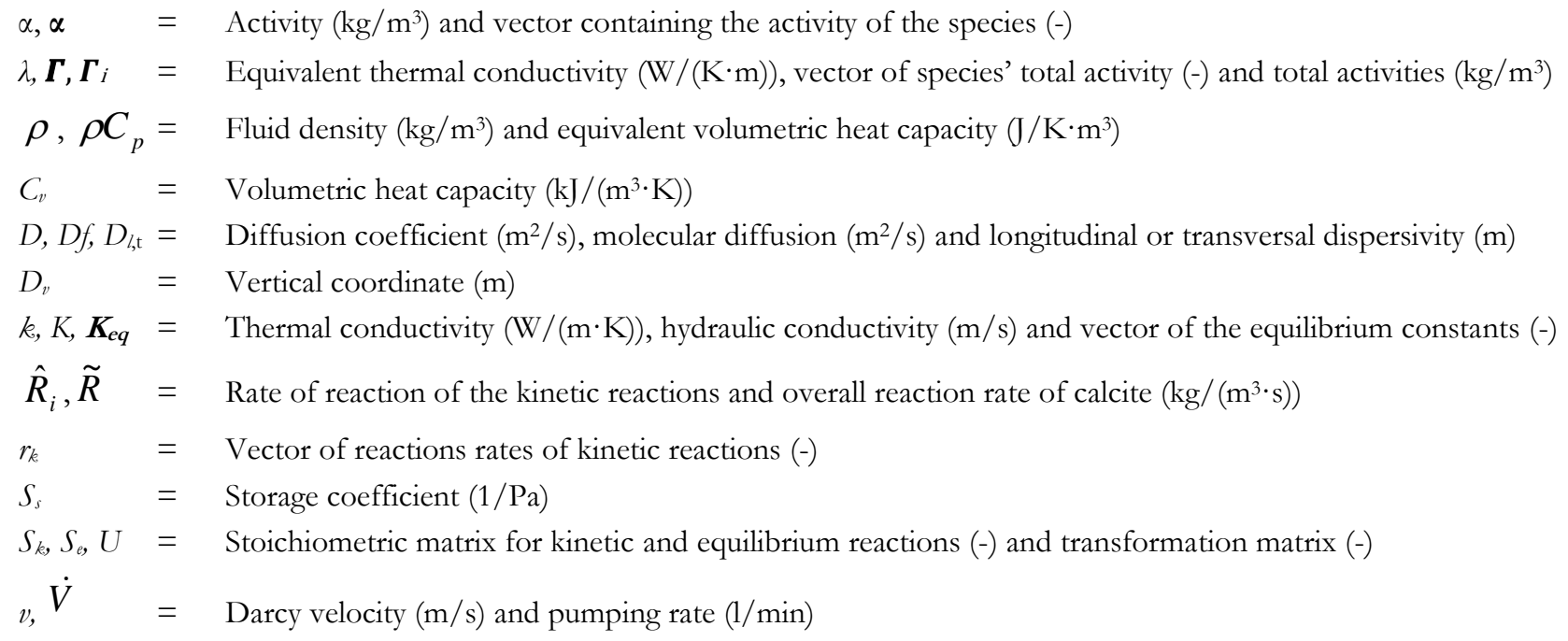




\section{REFERENCES}

Appelo, C.A.J. and D. Postma. 1993. Geochemistry, Groundwater and Pollution. Rotterdam, The Netherlands: A.A. Balkema.

Brantley, S.L, J.D. Kubicki and A.F. White. 2008. Kinetics of Water-Rock Interaction. New York, USA: Springer.

Eppner, F., P. Pasquier and P. Baudron. 2015. Development of a Thermo-Hydro-Geochemical Model for Low Temperature Geoexchange Applications. Proceedings of 2015 Comsol Conference. Boston, USA. October 5-7.

Eppner, F. 2016. Évolution thermos-hydro-géochimique d'un puits à colonne permanente conduisant à la précipitation et à la dissolution de la calcite. Ph.D. Thesis. Polytechnique Montréal.

Gunnlaugson, E. (2012). Scaling in Geothermal Installation in Iceland. Proceedings of short course on geothermal development and geothermal wells. Santa Tecla, El Salvado.

Holzbecher E. (2012). Environmental modeling using Matlab. Heidelberg, Germany: Springer Berlin Heidelberg.

Ma, Z., H. Yan, X. Zho and C. Hou. (2012). Impact of Carbonate Scaling on the Efficiency of Used Geothermal Water Reinjection from Low-Middle Temperature Geothermal Fluid in Xianyang Porous Geothermal Field, NW China. Advanced Materials Research307: 614-615.

Morel, F.M.M. and J.G. Hering. 1993. Principles and Applications of Aquatic Chemistry. Hoboken, United-States : WileyInterscience.

Nguyen, A., P. Pasquier and D. Marcotte. (2015). Influence of groundwater flow in fractured aquifers on standing column wells performance. Geothermics 58: 39-48.

Pasquier, P., A. Nguyen, F. Eppner, D. Marcotte and B. Baudron. 2016. Standing Column Wells. In S.J. Rees Advances in Ground-Source Heat Pump Systems, London: Woodhead Publishing.

Plummer, L., T. Wigley and D. Parkhurst. 1978. The Kinetics of Calcite dissolution in $\mathrm{CO}_{2}-$ water systems at 5 to $60{ }^{\circ} \mathrm{C}$ and 0 to 1 atm $\mathrm{CO}_{2}$. American Journal of Science 278: 179-216.

Saaltink M.W., C. Ayora and J. Carrera. (1998). A mathematical formulation for reactive transport that eliminates mineral concentrations. Water Resources Research 34: 1649-1656.

Stanasel, O., A. Iovi, H. Kristmannsdottir and I. Stanasel. (2006). Physical-Chemistry studies on Geothermal Waters and Scale Formations. Revue Roumaine de Chimie 51(3): 179-185. 